\title{
Application of Current Hemorrhage Control Techniques for Backcountry Care: Part Two, Hemostatic Dressings and Other Adjuncts
}

\author{
Lanny Littlejohn, MD, CDR, MC; Brad L. Bennett, PhD, NREMT-P; Brendon Drew, DO, CDR, MC \\ From the Emergency Medicine Department, Naval Medical Center Portsmouth, Portsmouth, VA (Dr Littlejohn); the Military and Emergency \\ Medicine Department, Uniformed Services University of the Health Sciences, F. Hébert School of Medicine, Bethesda, MD (Dr Bennett); and the \\ Emergency Medicine Department, Naval Medical Center San Diego, San Diego, CA (Dr Drew).
}

\begin{abstract}
Decade-long advances in battlefield medicine have revolutionized the treatment of traumatic hemorrhage and have led to a significant reduction in mortality. Part one of this review covered the use of tourniquets on the extremities and the newer devices for use in junctional areas. Part two focuses on the use of hemostatic agents or dressings, pelvic binders, and tranexamic acid. Field applicable hemostatic dressings are safe and effective in controlling hemorrhage not amenable to extremity tourniquet application, and newer agents with increasing efficacy continue to be developed. Most of these agents are inexpensive and lightweight, making them ideal products for use in wilderness medicine. The use of pelvic binders to stabilize suspected pelvic fractures has gained new interest as these products are developed and refined, and the prehospital use of tranexamic acid, a potent antifibrinolytic, has been found to be life saving in patients at risk of death from severe hemorrhage. Recommendations are made for equipment and techniques for controlling hemorrhage in the wilderness setting.
\end{abstract}

Key words: hemorrhage, hemostasis, trauma, prehospital, hemostatic agents, topical, dressing, bandage

\section{Introduction}

This review is the second of a two-part article translating recent advances in military and prehospital medicine to wilderness medicine care. Part one focused primarily on tourniquets, both extremity and junctional. Part two now turns to hemostatic dressings for control of compressible hemorrhage. We round out the discussion of other hemorrhage control adjuncts by reviewing pelvic fracture stabilization as well as the prehospital use of tranexamic acid (TXA) to assist in treating casualties at risk of lethal hemorrhage.

Disclaimer: The views expressed in this article are those of the authors and do not necessarily reflect the official policy or position of the Department of the Navy, Department of Defense, or the United States Government. L. Littlejohn and B. Drew are military service members. This work was prepared as part of their official duties. Title 17 U.S.C. 105 provides that copyright protection under this title is not available for any work of the United States Government. Title 17 U.S. C. 101 defines a United States Government work as a work prepared by a military service member or employee of the United States Government as part of that person's official duties.

Corresponding author: Brad L. Bennett, PhD, CAPT, US Navy (Ret.), PO Box 235, Bena, VA 23018 (e-mail: brad@wms.org).

\section{CASE PRESENTATION}

A climber was descending from the summit by glissading when he noticed that he was uncontrollably veering into a set of rocks. A poorly executed attempt at selfarrest with an ice axe resulted in a severe laceration to the left side of his neck before he crashed into the rocks below. You arrive several minutes later and note a significant amount of blood loss with the climber desperately trying to control the active bleeding from his injury while complaining of severe pelvic pain. Because of the area of injury, a tourniquet could not be used so you take a hemostatic dressing from your kit and begin to pack the injury firmly and reinforce the wound with a pressure dressing. No resources were available for air evacuation and self-extrication is the only viable alternative.

\section{Hemostatic Dressings}

The last decade has witnessed a surge of products designed to manage severe bleeding in areas not amenable to tourniquet application or when a tourniquet might be deemed inappropriate. Collectively, these 
products are termed hemostatic dressings, namely, gauze style dressings or powder or granular agents. However, despite a multitude of preclinical animal studies and numerous human case reports and series, no hemostatic dressing has emerged consistently as the best across all studies. In the prehospital phase, hemostatic dressings have the potential to reduce morbidity and mortality through the early control of hemorrhage. The ideal properties of a hemostatic agent for military use closely parallel those required for use in austere wilderness scenarios: lightweight, compact, simple to apply, durable under extreme conditions, long shelf life, inexpensive, safe, and effective. ${ }^{1}$

Two primary factors affect the efficacy of hemostatic products. The first is the mechanism of action. Some agents concentrate clotting factors at the site of injury, others form a mucoadhesive seal around the wound, and yet others are procoagulants that either activate the coagulation cascade or provide exogenous clotting factors to the injury site. ${ }^{2}$ The second factor affecting efficacy is the form in which the agent is delivered: wafer, granule, or gauze. The ability to conform to the wound geometry is essential to efficacy. Some agents may not conform well to complex wound geometry if the injury has a significant soft tissue defect (cavitary) whereas others may not be placed easily into smaller penetrating wounds from gunshot wounds or impalements.

In 2003, the first hemostatic agents selected by the Committee on Tactical Combat Casualty Care (CoTCCC), an organization that forms the foundation of US military prehospital combat care, were the HemCon bandage and then QuikClot granules. Continued testing of newer products by both US Army and US Navy laboratories found that Combat Gauze, WoundStat, and Celox were consistently more effective than the previously selected hemostatic agents. ${ }^{3-6}$ In 2008, Combat Gauze was selected as the first-line agent, with WoundStat recommended as the backup. However, subsequent animal safety studies showing extensive tissue inflammation, as well as embolization of the material in 1 subject, led to the removal of WoundStat from the CoTCCC guidelines. ${ }^{7}$ More hemostatic dressings are in development and testing, with encouraging results. $^{8-14}$ Table 1 provides an overview of first, second, and third generation hemostatic products designed for prehospital application.

\section{MECHANISMS OF ACTION}

Agents that concentrate clotting factors work through the rapid absorption of the water content of blood. That leaves remaining coagulation proteins and platelets at the site of the wound. The archetype product is QuikClot, adopted by the US Navy as its initial hemostatic agent of choice. It is a granular zeolite mineral that absorbs water, but it generates an exothermic reaction that has caused some safety concerns. ${ }^{15,16}$ A newer generation product with larger granules contained in small bags, Quikclot ACS + , does not lead to significant heat generation. ${ }^{17}$ Both TraumaDEX and BleedArrest are granular products that contain mucopolysaccharide hemispheres that absorb plasma to concentrate clotting factors and form a gel around the wound site. ${ }^{18}$

Mucoadhesive agents (chitosans) react with blood and wounded tissue to form a gluelike substance that effectively seals, or tamponades, the wound. Chitosan refers to a series of polymers derived from crustacean chitin. ${ }^{19}$ The hemostatic properties of chitosan appear to be formed by direct electrostatic interaction between negatively charged cell membranes of the erythrocytes and positively charged chitosan. These agents display strong adherence to tissues and physically seal bleeding wounds; hence, they act independently of the coagulation cascade. ${ }^{20,21}$ The archetype product here is the HemCon bandage, adopted by the US Army as its first-line hemostatic agent. Another chitosan-based agent is granular Celox. Because the mucoadhesive barrier is a physical phenomenon, there is a theoretical danger of rebleeding if an originally hypotensive patient is resuscitated to normal blood pressure. ${ }^{22}$

Procoagulants either activate the coagulation cascade or supply clotting factors at the site of injury. Combat Gauze, the only agent in this class approved by the Food and Drug Administration (FDA), is impregnated with kaolin, which activates the intrinsic pathway of coagulation. Salmon thrombin-fibrinogen (STF) dressing is a proprietary mixture of lyophilized salmon thrombin and fibrinogen, which is layered onto a water-soluble dressing composed of dextran. The action of STF is similar to that of human thrombin and fibrinogen and is applied directly to the injured vessel. The dextran immediately goes into solution upon contact with water (ie, blood), allowing hydration of the thrombin and fibrinogen molecules, which leads to polymerization into a fibrin clot. ${ }^{13,14,23}$ The FDA has not yet approved STF.

\section{FORM FACTORS}

The first hemostatic agents to be used by the US military had some undesirable properties that were not realized until utilized on the battlefield. The HemCon bandage was a rigid wafer difficult to adequately place in deep or smaller wounds. It could be cut with trauma shears, but even that made it difficult to apply. ${ }^{24}$ Granular agents such as QuikClot and WoundStat also posed problems. For the surgeon cleaning the wound, they were difficult 
Table 1. First, second, and third generation hemostatic agent or dressing

\begin{tabular}{|c|c|c|c|c|c|c|c|}
\hline Hemostatic agent & Gen. & $\begin{array}{l}\text { Comm. } \\
\text { Available }\end{array}$ & $\begin{array}{l}\text { CoTCCC } \\
\text { Approved }\end{array}$ & Composition & Mechanism of action & Form & Application \\
\hline $\begin{array}{l}\text { HemCon Bandage, } \\
\text { HemCon Medical } \\
\text { Technologies, Portland, } \\
\text { OR }\end{array}$ & $1 \mathrm{st}$ & Yes & $\begin{array}{l}\text { Yes; replaced } \\
\text { by Combat } \\
\text { Gauze April } \\
2008\end{array}$ & Chitosan & $\begin{array}{l}\text { Cross links RBCs to } \\
\text { form mucoadhesive } \\
\text { barrier }\end{array}$ & $\begin{array}{l}4 \times 4 \text { inch } \\
\text { wafer }\end{array}$ & $\begin{array}{l}\text { Place firmly over wound; } 3 \\
\text { min manual pressure. No } \\
\text { adverse effects; sticky to } \\
\text { handle. }\end{array}$ \\
\hline $\begin{array}{l}\text { QuickClot Granules, Z- } \\
\text { Medica, Wallingford, } \\
\text { CT }\end{array}$ & $1 \mathrm{st}$ & No & $\begin{array}{l}\text { Yes; replaced } \\
\text { by Combat } \\
\text { Gauze April } \\
2008 . \\
\text { Discontinued }\end{array}$ & Granular zeolite & $\begin{array}{l}\text { Rapidly absorbs water } \\
\text { in exothermic reaction } \\
\text { to concentrate clotting } \\
\text { factors }\end{array}$ & Volcanic rock & $\begin{array}{l}\text { Pour deep into wound, pack } \\
\text { standard gauze on top; } 3 \\
\text { min manual pressure. } \\
\text { Generates high temperature } \\
\text { with blood contact; will } \\
\text { cause burns. }\end{array}$ \\
\hline $\begin{array}{l}\text { BleedArrest, Hemostasis, } \\
\text { St. Paul, MN }\end{array}$ & 2nd & Yes & No & $\begin{array}{l}\text { Microporous } \\
\text { polysaccharide } \\
\text { "hemispheres" }\end{array}$ & $\begin{array}{l}\text { Absorbs plasma to } \\
\text { concentrate clotting } \\
\text { factors }\end{array}$ & $\begin{array}{l}\text { Granular, } \\
\text { multiple sizes }\end{array}$ & $\begin{array}{l}\text { Pour into wound; } 5 \text { min } \\
\text { manual pressure. No } \\
\text { adverse effects. }\end{array}$ \\
\hline $\begin{array}{l}\text { Celox Granules, MedTrade } \\
\text { Product, Crew, UK }\end{array}$ & 2nd & Yes & No & Chitosan & $\begin{array}{l}\text { Cross links RBCs to } \\
\text { form mucoadhesive } \\
\text { barrier }\end{array}$ & $\begin{array}{l}\text { Granular } \\
\text { chitosan }\end{array}$ & $\begin{array}{l}\text { Pour into wound; } 3 \text { min } \\
\text { manual pressure. No } \\
\text { adverse effects. Can be } \\
\text { hard to manage in windy } \\
\text { conditions. }\end{array}$ \\
\hline $\begin{array}{l}\text { Combat Gauze, Z-Medica, } \\
\text { Wallingford, CT }\end{array}$ & 2nd & Yes & Yes & $\begin{array}{l}\text { Kaolin- } \\
\text { impregnated } \\
\text { rolled gauze }\end{array}$ & $\begin{array}{l}\text { Activates intrinsic } \\
\text { pathway of coagulation }\end{array}$ & $\begin{array}{l}\text { Gauze, } 3 \text { in by } \\
12 \mathrm{ft}\end{array}$ & $\begin{array}{l}\text { Pack into wound; } 3 \text { min } \\
\text { manual pressure. No } \\
\text { adverse effects; users prefer } \\
\text { gauze over granules. }\end{array}$ \\
\hline $\begin{array}{l}\text { WoundStat, Trauma Cure, } \\
\text { Bethesda, MD }\end{array}$ & 2nd & No & $\begin{array}{l}\text { Yes; removed } \\
\text { owing to } \\
\text { safety } \\
\text { concerns }\end{array}$ & $\begin{array}{l}\text { Smectite } \\
\quad \text { (nonmetallic } \\
\text { clay) }\end{array}$ & $\begin{array}{l}\text { Absorbs fluid to form } \\
\text { clay material; } \\
\text { activates intrinsic } \\
\text { clotting pathway }\end{array}$ & Granular, $5.5 \mathrm{oz}$ & $\begin{array}{l}\text { Pour into wound, pack } \\
\text { manually to form clay; } 2 \\
\text { min manual pressure. }\end{array}$ \\
\hline $\begin{array}{l}\text { Celox Gauze, MedTrade } \\
\text { Products, Crew, UK }\end{array}$ & $3 \mathrm{rd}$ & Yes & Yes & Chitosan & $\begin{array}{l}\text { Cross links RBCs to } \\
\text { form mucoadhesive } \\
\text { barrier }\end{array}$ & $\begin{array}{l}\text { Rolled or Z- } \\
\text { fold, } 10 \text { feet }\end{array}$ & $\begin{array}{l}\text { Pack into wound; } 2 \text { min } \\
\text { manual pressure. No } \\
\text { adverse effects; end users } \\
\text { prefer gauze over granules. }\end{array}$ \\
\hline $\begin{array}{l}\text { ChitoGauze, HemCon } \\
\text { Medical Technologies, } \\
\text { Portland, OR }\end{array}$ & $3 \mathrm{rd}$ & Yes & Yes & Chitosan & $\begin{array}{l}\text { Cross links RBCs to } \\
\text { form mucoadhesive } \\
\text { barrier }\end{array}$ & Z-fold, 12 feet & $\begin{array}{l}\text { Pack into wound; } 2 \text { min } \\
\text { manual pressure. No } \\
\text { adverse effects; users prefer } \\
\text { gauze over granules. }\end{array}$ \\
\hline $\begin{array}{l}\text { Salmon Thrombin } \\
\text { Fibrinogen, St. Teresa } \\
\text { Medical, Woodbury, } \\
\text { MN }\end{array}$ & $3 \mathrm{rd}$ & No & No & $\begin{array}{c}\text { Lyophilized STF } \\
\text { sealed in water- } \\
\text { soluble dextran }\end{array}$ & $\begin{array}{l}\text { Thrombin hydration and } \\
\text { fibrinogen polymeri- } \\
\text { zation into fibrin clot }\end{array}$ & $\begin{array}{l}\text { Dextran-bound } \\
\text { STF packs }\end{array}$ & $\begin{array}{l}\text { Pack into wound; } 2 \text { min } \\
\text { manual pressure. }\end{array}$ \\
\hline
\end{tabular}

Gen., generation; Comm., commercially; CoTCCC, Committee on Tactical Combat Casualty Care; RBC, red blood cells; STF, salmon thrombin-fibrinogen. 
to debride. For the medic in the field, helicopter rotor wash and high wind weather conditions often found the granular products being dispersed or getting into the eyes of first responders. For these reasons, most of the current recommendations are for some type of hemostatic gauze product that can easily be placed into any type of wound, is easy to remove, and is effective under all environmental conditions.

Recent research into several newer hemostatic gauze dressings show promising findings. The Naval Medical Research Unit San Antonio recently compared 5 gauze products: 2 versions of Combat Gauze (standard 3 inch and XL 4 inch), Celox Gauze, Celox Trauma Gauze, and HemCon's ChitoGauze. This study found that the Combat Gauze XL product showed improved initial hemostasis over standard Combat Gauze (control) whereas both Combat Gauze XL and Celox Gauze showed significant improvement over control in hemostasis at 10 minutes. ${ }^{9}$ Schwartz et $\mathrm{al}^{8}$ compared Combat Gauze with ChitoGauze in a swine model and found ChitoGauze to be faster for initial hemostasis, with less total blood loss and fluid resuscitation requirements. Celox Trauma Gauze has now been replaced by Celox Rapid, a chitosan gauze dressing that has shown a faster application time and less blood loss when compared with Combat Gauze. ${ }^{12}$

\section{CLINICAL EVIDENCE}

Existent clinical evidence comes from case reports and case series. In 2006, Wedmore ${ }^{25}$ published a case series of HemCon bandage use by medics with data gathered in the form of a retrospective questionnaire. There were 64 uses, with two thirds of these uses occurring after standard treatment had failed. There was an overall success rate of $97 \%$ in this series, and the 2 failures occurred in deep cavitary wounds where there was difficulty in appropriate placement of the dressing. ${ }^{25}$ Another HemCon case series from a civilian Emergency Medical Services system has also been published. Thirty-four cases are described, 18 on the extremities and 13 above the neck; there was a $74 \%$ success rate in controlling hemorrhage and 7 failures. User error was sited in 6 of 7 of these failures, emphasizing the need for adequate training and skills retention. The largest case series on the original QuikClot granular product was by Rhee et al. ${ }^{26}$ Of the 103 cases reported, 83 were external (versus surgical wounds inside body cavities), and all first responder uses were successful. A case series of Combat Gauze use reported a 79\% success rate in arrest of hemorrhage, with no adverse effects observed. Failures were in the neck, buttock, and thigh where there were large soft tissue injuries along with major vascular injury. ${ }^{27}$

\section{SAFETY}

The FDA views hemostatic agents as class II medical devices. These products secure approval by proving that they are equivalent to similar agents already approved for short-term external hemorrhage control. Because safety testing focuses on an adverse effect of chemicals from the device and not on agent biocompatibility, or on whether they are safe for vascular injuries with access to the systemic circulation, current testing may be inadequate for agents that are granular or prothrombotic. The first safety concerns had arisen with respect to the original QuickClot formulation and WoundStat-both granular products. QuickClot granules have been documented to cause thermal injuries ranging from second degree burns ${ }^{28}$ to burns that required skin grafting. ${ }^{26}$ One case of ureteral injury requiring delayed repair was also published, but this patient was also a survivor of severe trauma where QuickClot granules application was purportedly life-saving. ${ }^{29}$ WoundStat has been shown to lead to significant vascular inflammation and an inability to successfully repair vascular injuries after its use. In a neck injury model, WoundStat also showed evidence of distal emboli to the lungs. This same study also evaluated Combat Gauze and found no significant histologic changes with this product and no distal thromboembolism. ${ }^{7}$ The QuickClot and WoundStat granules are no longer commercially available.

\section{CURRENTLY RECOMMENDED AGENTS}

Because of the efficacy concerns with the HemCon bandage and the safety concerns with the original granular QuikClot and WoundStat, the CoTCCC currently recommends Combat Gauze as the only hemostatic dressing that has passed both efficacy and safety testing. Combat Gauze dressing remains the hemostatic dressing with the most definitive safety evidence to support its use, along with no reported side effects from use on the battlefield and other locations. Further research into the efficacy and safety of other hemostatic dressings may give further options for prehospital use, particularly for the coagulopathic patient who has become both hypothermic and acidotic from significant hemorrhage.

Recently, Bennett and Littlejohn ${ }^{30}$ reviewed the third generation hemostatic dressings for effectiveness and safety and have recommended that the chitosan-based dressings Celox Gauze and ChitoGauze be added to the list of approved hemostatic agents within the TCCC guidelines. These 2 dressings come with documented 
effectiveness and safety in preclinical animal studies and with extensive battlefield application to casualties by United Kingdom Ministry of Defense personnel and other NATO militaries with no reported complications. Based on the evidence presented in this paper, in March 2014, the CoTCCC membership voted to add Celox Gauze and ChitoGauze to the TCCC trauma guidelines. ${ }^{30}$

\section{PRACTICAL USE OF HEMOSTATIC DRESSINGS}

All 3 gauze hemostatic dressings-Combat Gauze, Celox Gauze, and ChitoGauze - are applied in a similar manner. Active areas of hemorrhage should be controlled initially with manual direct pressure to arrest active hemorrhage while the dressing is removed from the package. One end of the dressing is then placed immediately over the area within the wound where active hemorrhage is seen, taking care to continue to pack the entire dressing steadily and firmly with the free hand while the other hand continues to hold pressure so that no further bleeding ensues. Once the dressing is completely packed deep into the wound, direct pressure is firmly held for 3 to 5 minutes. After this, it is important to overpack the wound with enough additional dressing (or regular gauze on top of the hemostatic dressing if needed) so that an elastic type pressure dressing can be applied in a manner that will supplement the pressure of this last maneuver. Several commercially available pressure dressings, such as Emergency Trauma Dressing or even a 3-inch Ace wrap, will serve as well. If rebleeding occurs, it may be necessary to tighten the pressure dressing. If that fails, then all dressing material should be removed and a new hemostatic dressing applied in the same manner. (Further explanation of these procedures can be found in the TCCC guidelines and curriculum at: http://www.naemt.org/education/TCCC/tccc.aspx.)

\section{Pelvic Fracture Hemorrhage}

Fracture reduction and stabilization have long been conjectured to assist with pain control as well as decrease hemorrhage. Because the most lethal source of hemorrhage from a fracture occurs from injuries to the pelvic ring, no discussion of hemorrhage control in the austere setting would be complete without this emphasis. Pelvic fractures from falls are a real possibility in the wilderness setting, and pelvic fracture mortality is reported to be from $7.6 \%$ to $19 \%$ for patients who reach the hospital. ${ }^{31-33}$ Exsanguinating hemorrhage is the cause of death during the first 24 hours after injury, and multiorgan failure results in the majority of deaths after this period. ${ }^{34}$

Most traumatologists today believe that hemorrhage control from pelvic binding is most likely due to decreased pelvic motion and stabilization of the sacral venous plexus, allowing newly formed soft thrombus to remain intact, rather than decreased size of the potential space in which hemorrhage can occur. Lee and Porter ${ }^{35}$ provide the best evidence-based guidelines for pelvic fracture management, and these guidelines can be adapted for use in the wilderness setting (Table 2). They note that performing a physical examination is poor, with sensitivity of 59\% and specificity of $71 \%$ for routine "springing" of the pelvis, and that this act, along with routine logrolling of patients with suspected pelvic fractures, should be abandoned. For prehospital providers, they suggest that a combination of mechanisms, such as a fall from a height and pain in the pelvic area, should suffice to consider immobilizing the pelvis. Several commercially available pelvic binders are small, lightweight, and easy to apply. ${ }^{36-38}$ Although the hemorrhage control controversy continues owing to the lack of prospective studies, ${ }^{39}$ a pelvic wrap or binder, and adduction with internal rotation of the legs, will stabilize the fracture and may decrease bleeding while awaiting medical transport. ${ }^{40,41}$ Two of the junctional tourniquets, covered in part one of this series, also incorporate a pelvic binder into their design to assist in pelvic fracture stabilization.

Without a commercial pelvic splint, the most expeditious way to stabilize a pelvic fracture is to improvise

Table 2. Principles of prehospital pelvic fracture management ${ }^{a}$

1. Determine mechanism of injury (eg, fall from height).

2. If any complaint or presence of pain in pelvic, back, or groin regions, immobilize pelvis.

3. Examination is unreliable with decreased Glasgow Coma Scale score or any distracting injuries (eg, fracture); to avoid further internal hemorrhage, pelvis should not be palpated.

4. With any suspicion of fracture, immobilize pelvis using external compression splint (commercial device or improvised binder, eg, clothes, sleeping bag, or poncho liner).

5. Do not fully log roll the patient.

6. Ideally, use scoop stretcher to facilitate patient's movement onto spinal board or vacuum mattress for transport in litter.

7. Fluid resuscitation to maintain radial pulse only (hypotensive resuscitation).

8. Do not remove pelvic splint for suspected unstable pelvic injury until radiologically confirmed there is no fracture.

\footnotetext{
${ }^{a}$ Modified from Lee and Porter. ${ }^{42}$
} 
external pelvic compression with the use of a longitudinally folded sheet, trousers, or jacket wrapped circumferentially around the pelvis and tied over the center of the pelvis, with a windlass through the central knot to tighten and secure the resulting tension. The improvised or commercial binder should be centered over the greater trochanters rather than over the iliac crests for effective stabilization. ${ }^{42}$ The legs should be internally rotated and immobilized together to assist in reducing any suspected fracture. Once applied, pelvic binders should not be removed until after radiographic evaluation.

\section{Prehospital Use of Tranexamic Acid}

The acute coagulopathy of trauma is beginning to be recognized as a significant factor in the morbidity and mortality of the injured victim with traumatic hemorrhage. Recent reports show that coagulation derangements are present on presentation to the emergency department in $38 \%$ of combat casualties requiring blood transfusion ${ }^{43}$ and in $25 \%$ of civilian trauma victims ${ }^{44}$ presenting to a level I trauma center. Although the causes of coagulopathy are multifactorial (consumption of factors and platelets, dilutional from prehospital resuscitation, hypothermia, acidosis, inflammatory), the etiology of this initial coagulopathy appears to be primarily fibrinolytic (increased fibrinolysis), particularly when standard prehospital resuscitation strategies are followed..$^{45}$ If that is true, then stabilizing initial thrombus, like that formed in a reduced and stabilized pelvic fracture, with an antifibrinolytic such as TXA makes sense. Several recent studies have shown this to be effective therapy to decrease mortality from hemorrhage in trauma patients. ${ }^{46-49}$

The largest and most important study was the Effects of Tranexamic Acid on Death, Vascular Occlusive Events, and Blood Transfusion in Trauma Patients With Significant Hemorrhage (CRASH-2) trial, ${ }^{46}$ a prospective, randomized, controlled trial of 20,211 patients with significant hemorrhage from trauma or at risk of significant hemorrhage. Patients who met inclusion criteria were given $1 \mathrm{~g}$ TXA over 10 minutes within 8 hours of injury, and then $1 \mathrm{~g}$ as an infusion over 8 hours after the first dose. Absolute risk reduction was significant in this trial. ${ }^{47}$ Early treatment with TXA is important. The CRASH-2 trial analysis showed a significant survival advantage if given within 1 hour of injury $(P<.0001)$. If given from 1 to 3 hours after injury, the significant survival advantage fell (to $P=$ $.03)$. Given after the 3-hour point, the risk of death due to bleeding increased $(P=.004){ }^{48}$ No statistical difference was seen in thrombotic complications between the TXA and placebo groups.
The Military Application of Tranexamic Acid in Trauma Emergency Resuscitation (MATTERs) trial was a retrospective study of 896 patients who required a blood transfusion received at Camp Bastion, a large Combat Support Hospital in Helmand Province, Afghanistan. ${ }^{49}$ In all, 293 casualties received TXA. The TXA group had a lower unadjusted mortality $(P=.03)$ despite being more severely injured (higher Injury Severity Score, $P<.001)$. Benefit was greatest in a subgroup who received a massive transfusion $(P=.004)$. Use of TXA was independently associated with survival (CI: 3 to 17$)$ and less coagulopathy $(P=.003)$.

In adverse weather conditions and other wilderness settings with prolonged evacuation times, TXA may be an important adjunct to controlling hemorrhage in traumatized patients. The TCCC guidelines recommend that any patient with significant hemorrhage resulting in abnormal vital signs or any patient at risk for significant hemorrhage, such as a pelvic fracture or evidence of intraabdominal bleeding, be given the first dose of TXA at the point of injury, ideally within the first hour after injury but not later than 3 hours. It is effectively administered in $100 \mathrm{~mL}$ normal saline over 10 minutes through an IV or intraosseous (IO) device. Current research and development efforts are under way to determine whether TXA can be delivered by an autoinjector.

\section{PUTTING IT ALL TOGETHER}

Control of hemorrhage in the prehospital setting has made significant advancements in the past decade. A recent evidence-based guideline for hemorrhage control put forth by the American College of Surgeons Committee on Trauma advocates the use of tourniquets and hemostatic agents in the prehospital setting. The Figure is a simplified hemorrhage control algorithm modified for backcountry use from this guideline. ${ }^{50}$ In Table 3, we recommend hemorrhage control items for an individual and medical evacuation team/medical expedition team for use in austere environments.

\section{CASE RESOLUTION}

As an advanced wilderness medicine practitioner, you had a complete medical kit in your pack that included TXA and an IV starter kit. Because the victim complained of pelvic pain, you improvised a pelvic binder with a jacket and also an improvised windlass, and then administered $1 \mathrm{~g}$ TXA over 10 minutes in a $100 \mathrm{~mL}$ bag of normal saline and assisted the injured to the base of the mountain on an improvised litter. $\mathrm{He}$ was then transported by ground ambulance to a nearby emergency department, arriving several hours after the initial injury. Although mildly hypothermic and slightly acidotic from the initial blood loss, he was successfully rewarmed and 
Actively bleeding wound identified - Apply direct pressure and/or pressure dressing to injury
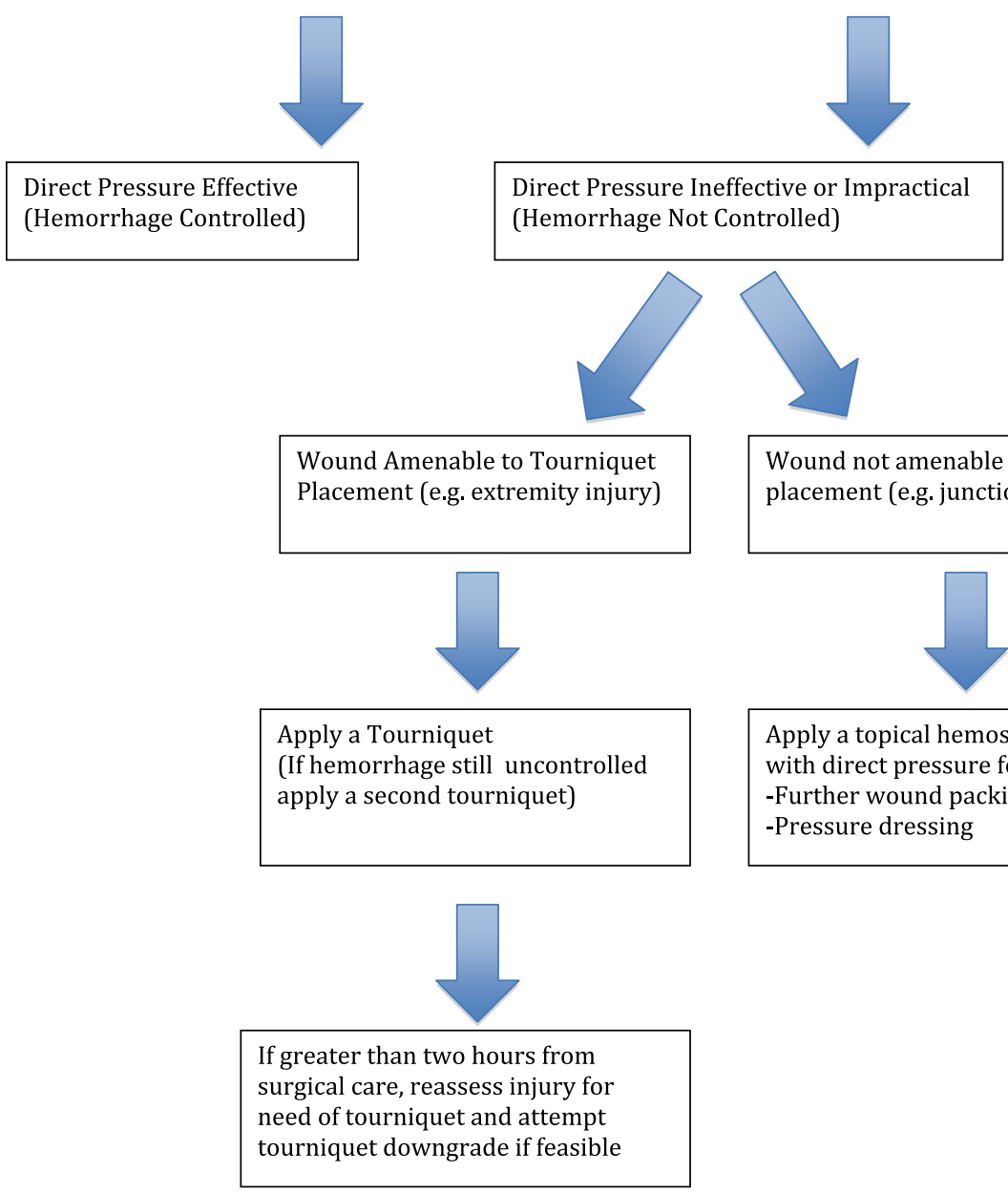

Wound Amenable to Tourniquet

Wound not amenable to tourniquet placement (e.g. junctional injury)

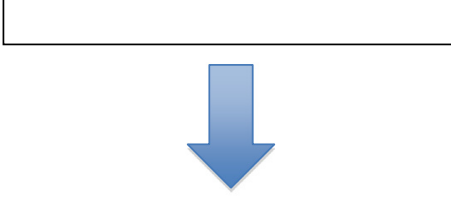

Apply a topical hemostatic agent with direct pressure followed by: -Further wound packing if needed -Pressure dressing

Figure. A simplified hemorrhage control algorithm, modified for backcountry use, from the American College of Surgeons Committee on Trauma guideline.

Table 3. Recommendations for hemorrhage control kit

\begin{tabular}{|c|c|c|}
\hline Individual kit $^{a}$ & Evacuation/medical expedition kit & Comments \\
\hline 2 rolls gauze & $b$ & Use standard gauze roll or Z-folded; vacuum packed. \\
\hline 2 pressure dressings & $b$ & Recommend commercial military trauma pressure dressing. \\
\hline 2 hemostatic dressings & $b$ & Carry CoTCCC-approved dressings. ${ }^{c}$ \\
\hline \multirow[t]{5}{*}{2 tourniquets } & $b$ & Carry CoTCCC-approved tourniquet. ${ }^{c}$ \\
\hline & 1 junctional tourniquet & Carry CoTCCC approved junctional tourniquet. ${ }^{c}$ \\
\hline & 1 abdominal tourniquet & $\begin{array}{l}\text { Only } 1 \text { abdominal aortic tourniquet FDA approved: } \\
\text { Compression Works (http://www.compressionworks.net/). }\end{array}$ \\
\hline & 1 pelvic sling & Carry CoTCCC-approved pelvic sling. ${ }^{c}$ \\
\hline & 2 TXA IV kits & See approved CoTCCC guidelines for TXA. ${ }^{c}$ \\
\hline
\end{tabular}

CoTCCC, Committee on Tactical Combat Casualty Care; FDA, Food and Drug Administration; TXA, tranexamic acid; IV, intravenous

${ }^{a}$ Minimum items recommended for individual carry.

${ }^{b}$ Carry the same items as for individual but in greater quantity.

${ }^{c}$ Available at: http://www.naemt.org/education/TCCC/tccc.aspx. 
resuscitated before definitive surgery on his vascular injury. No pelvic fracture was found, and he was discharged without complications on hospital day 3 .

\section{Conclusion}

It is clear that a hemorrhage control first aid kit for the wilderness medicine environment has moved well beyond gauze and tape. In part one of this series, specific recommendations were made regarding prehospital tourniquets. A review of the literature on hemostatic dressings revealed that Combat Gauze has the most evidence for safe and effective use in controlling hemorrhage, but newer FDA-approved chitosan-based gauze hemostatic dressing, Celox Gauze and ChitoGauze, have shown efficacy in preclinical testing and are reported to be safe and effective for short-term external application. Firm wound packing and pressure dressings should always be applied when a hemostatic agent is used. Pelvic binding is an often-overlooked critical action that should be performed in the setting of appropriate mechanism of injury and the presence of pelvic or groin pain. Early administration of TXA has been shown to decrease mortality of trauma victims at risk of death due to hemorrhage. Further active research in hemorrhage control methods and devices for the battlefield trauma application will continue to yield innovations that can be applied to the austere wilderness setting.

\section{References}

1. Pusateri AE, Holcomb JB, Kheirabadi BS, et al. Making sense of the preclinical literature on advanced hemostatic products. J Trauma. 2006;60:674-682.

2. Granville-Chapman J, Jacobs N, Midwinter MJ. Prehospital haemostatic dressings: a systematic review. Injury. 2011;42:447-459.

3. Kheirabadi BS, Edens JW, Terrazas IB, et al. Comparison of new hemostatic granules/powders with currently deployed hemostatic products in a lethal model of extremity arterial hemorrhage in swine. J Trauma. 2009;66:316-326.

4. Kheirabadi BS, Scherer MR, Estep JS, et al. Determination of efficacy of new hemostatic dressings in a model of extremity arterial hemorrhage in swine. J Trauma. 2009;67:450-459.

5. Arnaud F, Parreno-Sadalan D, Tomori T, et al. Comparison of 10 hemostatic dressings in a groin transection model in swine. J Trauma. 2009a;67:848-855.

6. Arnaud F, Teranishi K, Tomori T, et al. Comparison of 10 hemostatic dressings in a groin puncture model in swine. J Vasc Surg. 2009b;50:632-639.

7. Kheirabadi BS, Mac EJE, Terrazas IB, et al. Safety evaluation of new hemostatic agents, smectite granules, and kaolin-coated gauze in a vascular injury wound model in swine. J Trauma. 2010;68:269-277.
8. Schwartz RB, Reynolds BZ, Shiver SA, et al. Comparison of two packable hemostatic gauze dressings in a porcine hemorrhage model. Prehosp Emerg Care. 2011;15:477-482.

9. Rall JM, Cox JM, Adam Songer A, et al. Comparison of novel hemostatic gauzes to QuikClot Combat Gauze in a standardized swine model of uncontrolled hemorrhage: Naval Medical Research Unit, 2012:TR22. Available at: http://www.scribd.com/doc/87902673/namru-sa-technicalreport-2012-22-30-mar-12. Accessed April 5, 2013.

10. Hoggarth A, Hardy C, Lyon A. Testing a new gauze hemostat with reduced treatment time. Advanced Technology Applications for Combat Casualty Care Conference 2011, abstract. Available at: http://www.celoxmedical. $\mathrm{com} / \mathrm{wp}$-content/uploads/celox-rapid-reduced-compressiontime-poster.pdf. Accessed May 22, 2014.

11. Xie H, Lucchesi L, Teach J, et al. Comparison of hemostatic efficacy of ChitoGauze and Combat Gauze in a lethal femoral arterial injury in swine model. Advanced Technology Applications for Combat Casualty Care Conference, 2011. Available at: http://ftp.rta.nato.int/public// pubfulltext/rto/mp/rto-mp-hfm-182///mp-hfm-182-25.doc. Accessed May 22, 2014.

12. Kunio NR, Riha GM, Watson KM, et al. Chitosan based advanced hemostatic dressing is associated with decreased blood loss in a swine uncontrolled hemorrhage model. Am J Surg. 2013;205:505-510.

13. Floyd CT, Rothwell SW, Martin R, Risdahl J, Olson CE. A salmon thrombin-fibrinogen dressing controls hemorrhage in a swine model compared to standard kaolincoated gauze. J Spec Oper Med. 2012;12:49-55.

14. Floyd CT, Rothwell SW, Risdahl J, Martin R, Olson C, Rose N. Salmon thrombin-fibrinogen dressing allows greater survival and preserves distal blood flow compared to standard kaolin gauze in coagulopathic swine with a standardized lethal femoral artery injury. J Spec Oper Med. 2012;12:16-26.

15. Arnaud F, Tomori T, Saito R, et al. Comparative efficacy of granular and bagged formulations of the hemostatic agent QuikClot. J Trauma. 2007;63:775-782.

16. Pusateri AE, Delgado AV, Dick EJ, et al. Application of a granular mineral-based hemostatic agent (QuikClot) to reduce blood loss after grade $\mathrm{V}$ liver injury in swine. J Trauma. 2004;57:555-562.

17. Arnaud F, Tomori T, Carr W, et al. Exothermic reaction in zeolite hemostatic dressings: QuikClot ACS and ACS+. Ann Biomed Eng. 2008;36:1708-1713.

18. Gegel B, Burgert J, Cooley B, et al. The effects of BleedArrest, CELOX, and TraumaDEX on hemorrhage control in a porcine model. J Surg Res. 2010;164:125-129.

19. Aiba S. Studies on chitosan: 4. Lysozymic hydrolysis of partially $\mathrm{N}$-acetylated chitosans. Int J Biol Macromol. 1992;14:225-228.

20. Rao SB, Sharma CP. Use of chitosan as a biomaterial: studies on its safety and hemostatic potential. J Biomed Mater Res. 1997;34:21-28.

21. Mizadehl H, Yaghobi N, Amanpour S, et al. Preparation of chitosan derived from shrimp shell of Persian Gulf as a blood hemostasis agent. Iranian Polymer J. 2002;11(64):63-68. 
22. Kheirabid BS, Acheson EM, Deguzman R, et al. Hemostatic efficacy of two advanced dressings in an aortic hemorrhage model in swine. $J$ Trauma. 2005;59: 25-35.

23. Rothwell SW, Reid TJ, Dorsey J, et al. A salmon thrombin-fibrin bandage controls arterial bleeding in a swine aortotomy model. J Trauma. 2005;59:143-149.

24. Brown MA, Daya MR, Worley JA. Experience with chitosan dressings in a civilian EMS system. J Emerg Med. 2009;37:1-7.

25. Wedmore I, McManus JG, Pusateri AE, Holcomb JB. A special report on the chitosan-based hemostatic dressing: experience in current combat operations. J Trauma. 2006;60:655-658.

26. Rhee P, Brown C, Martin M, et al. QuikClot use in trauma for hemorrhage control:cases series of 103 documented uses. J Trauma. 2008;64:1093-1099.

27. Ran Y, Hadad E, Daher S, et al. QuikClot combat gauze use for hemorrhage control in military trauma: January 2009 Israel Defense Force experience in the Gaza Strip-a preliminary report of 14 cases. Prehosp Disaster Med. 2010;25:584-588.

28. McManus J, Hurtado T, Pusateri A, Knoop KJ. A case series describing thermal injury resulting from zeolite use for hemorrhage control in combat operations. Prehosp Emerg Care. 2007;11:67-71.

29. Plurad D, Chandrasoma S, Best C, et al. A complication of intracorporeal use of QuikClot for pelvic hemorrhage. $J$ Trauma. 2009;66:1482-1484.

30. Bennett BL, Littlejohn L, Kheirabadi B, et al. Management of external hemorrhage in tactical combat casualty care: chitosan-based hemostatic gauze dressings. J Spec Oper Med. 2014;14:21-38.

31. Poole GV, Ward EF. Causes of mortality in patients with pelvic fractures. Orthopaedics. 1994;17:691-696.

32. Rothenberger DA, Fischer RP, Strate RG, et al. The mortality associated with pelvic fractures. Surgery. 1978;84:356-361.

33. Chong KH, DeCoster T, Osler T, et al. Pelvic fractures and mortality. Iowa Orthop J. 1997;17:110-114.

34. White CE, Hsu JR, Holcomb JB. Haemodynically unstable pelvic fractures. Injury Int J Care Injured. 2009;40:10231030 .

35. Lee C, Porter K. The prehospital management of pelvic fractures. Emerg Med J. 2007;24:130-133.

36. Knops SP, VanLieshout EM, Spanjersberg WR, Patka P, Schipper IB. Randomised clinical trial comparing pressure characteristics of pelvic circumferential compression devices in healthy volunteers. Injury Int $J$ Care Injured. 2011;42:1020-1026.

37. Knops SP, van Riel MP, Goossens RH, van Lieshout EM, Patka P, Schipper IB. Measurements of the exerted pressure by pelvic circumferential compression devices. Open Orthoped J. 2010;4:101-106.

38. Knops SP, Schep NW, Spoor CW, van Riel MP, Spanjersberg WR, Kleinrensink GJ, et al. Comparison of three different pelvic circumferential compression devices: a biomechanical cadaver study. J Bone Joint Surg Am. 2011;93:23-24.

39. Steward M. Pelvic circumferential compression devices for hemorrhage control: panacea or myth? Emerg Med J. 2013;30:425-426.

40. American College of Surgeons Committee on Trauma. Musculoskeletal trauma. In: Advanced Trauma Life Support. 8th ed. Chicago, IL: American College of Surgeons; 2008:192-193.

41. Gardner MJ, Parada S, Routt ML. Internal rotation and taping of the lower extremities for closed pelvic reduction. J Orthop Trauma. 2009;23:361-364.

42. Spanjersberg WR, Knops SP, Schep NW, van Lieshout EM, Patka P, Schipper IB. Effectiveness and complications of pelvic circumferential compression devices in patients with unstable pelvic fractures. Injury Int J Care Injured. 2009;40:1031-1035.

43. Niles SE, McLaughlin DF, Perkins JF, et al. Increased mortality associated with the early coagulopathy of trauma in combat casualties. J Trauma. 2008;64:1459-1465.

44. Brohi K, Singh J, Heron M, et al. Acute traumatic coagulopathy. J Trauma. 2003;54:1127-1130.

45. Bollinger D, Szlam F, Levy J, et al. Haemodilutioninduced profibrinolytic state is mitigated by fresh-frozen plasma: implications for early haemostatic intervention in massive hemorrhage. Br J Anaesth. 2010;104:318-325.

46. Shakur H, Roberts I, Bautista R, et al. Effects of tranexamic acid on death, vascular occlusive events, and blood transfusion in trauma patients with significant hemorrhage (CRASH-2): a randomized, placebocontrolled trial. Lancet. 2010;376:23-32.

47. Roberts I, Perel P, Prieto-Merino D, et al. Effect of tranexamic acid on mortality in patients with traumatic bleeding: prespecified analysis of data from randomized controlled trial. BMJ. 2012;345:e5839.

48. Roberts I, Shakur H, Afolabi A, et al. The importance of early treatment with tranexamic acid in bleeding trauma patients: an exploratory analysis of the CRASH-2 randomised controlled trial. Lancet. 2011;377:1096-1101.

49. Morrison JJ, Dubose JJ, Rasmussen TE, et al. Military Application of Tranexamic Acid in Trauma Emergency Resuscitation (MATTERs) study. Arch Surg. 2012;147: 113-119.

50. Bulgar EM, Snyder D, Schoelles K, et al. An evidencebased prehospital guideline for external hemorrhage control. American College of Surgeons Committee on Trauma. Prehosp Emerg Care. 2014;18:163-173. 